\title{
Sensemaking epistemic game: A model of student sensemaking processes in introductory physics
}

\author{
Tor Ole. B. Odden ${ }^{*}$ \\ Department of Physics, Center for Computing in Science Education, University of Oslo, \\ Sem Salands vei 24, 0316 Oslo, Norway \\ Rosemary S. Russ \\ Department of Curriculum and Instruction, University of Wisconsin, \\ Madison, 225 N. Mills St., Madison, Wisconsin 53706, USA
}

(Received 16 January 2018; published 29 November 2018)

\begin{abstract}
Although physics teachers often seek to help their students make sense of physics concepts, our field has yet to thoroughly explore how and why students engage in sensemaking. In this study we use the epistemic games framework to propose a model for students' sensemaking processes. Our analysis of a series of clinical interviews with introductory physics students discussing electricity and magnetism topics suggests the goal of this sensemaking game is to iteratively construct an explanation in response to a perceived gap or inconsistency in knowledge. We illustrate the model with a case study of two students discussing electric current and use that case to outline the entry conditions, exit conditions, and several moves and constraints within this sensemaking game. We conclude by arguing for the utility of this model in designing learning environments that support sensemaking and in directing future sensemaking-focused research.
\end{abstract}

DOI: 10.1103/PhysRevPhysEducRes.14.020122

\section{INTRODUCTION}

As physics instructors, we all want our students to make sense of the ideas they encounter in our courses. And, for good reason; sensemaking has been shown to help students both build new knowledge and create connections within the knowledge they already have [1-3]. The process of sensemaking also helps students to achieve coherence between their everyday understanding and their formal physics knowledge, keeping them from mentally "walling off" physics from the "real world" [4-6]. Furthermore, students who aim to make sense of physics, viewing it as a set of interconnected principles rather than a jumble of equations, are well on their way to an expertlike epistemology of physics [7-9].

Physics education researchers have had little trouble locating examples of sensemaking to analyze. Numerous studies have documented snapshots of student sensemaking (see, e.g., Refs. $[1,2,5,10]$ ) providing an ever-growing list of the hallmarks of this process. However, though the

\footnotetext{
Corresponding author. t.o.odden@fys.uio.no

Published by the American Physical Society under the terms of the Creative Commons Attribution 4.0 International license. Further distribution of this work must maintain attribution to the author(s) and the published article's title, journal citation, and DOI.
}

research literature provides many ways to identify sensemaking, eliciting and sustaining it are an entirely different matter. We are able to recognize sensemaking as it is happening, yes, but we do not yet know how to reliably make it occur, or how it proceeds once it has begun.

This is a problem because if properly harnessed, sensemaking has the potential to be another powerful tool in our pedagogical toolbox. We could, for example, use it to design curricula and learning environments, similar to other approaches based on principles like guided inquiry $[11,12]$, active learning $[13,14]$, personal epistemology $[8,15,16]$, modeling [17-19], and analogical scaffolding [20,21]. However, if we have not mapped the process-if we do not know how it begins, proceeds, and ends-it will be difficult to build into physics courses.

Our present study addresses this problem by proposing a model for the process that students go through when sensemaking, from beginning to end. Using a case study from a series of cognitive clinical interviews that primed and captured episodes of sensemaking, we argue that sensemaking can manifest as a distinct, bounded process which unfolds in a characteristic way. We then describe this process using the same theoretical machinery used elsewhere in physics education research (PER) to describe other varieties of student inquiry, the epistemic games framework, and further use this framework to tease out the parameters of the sensemaking "game." 


\section{LITERATURE REVIEW AND THEORETICAL FRAMEWORK}

\section{A. What is sensemaking?}

There is a substantial amount of science education research literature that aims to define and characterize scientific sensemaking. Elsewhere [22] we have argued that this body of literature, when taken as a whole, conceptualizes sensemaking in three different ways: as a stance or frame towards science learning, a cognitive process, and a discourse practice.

Generally speaking, framing is a term borrowed from the sociology, linguistics, and psychology literature, referring to how individuals or groups of people answer the question "what's going on here?" $[23,24]$. From a framing perspective, sensemaking is a way in which students approach science learning, which is characterized by trying to "figure something out" using one's prior knowledge. That is to say, when students are sensemaking their "task" is to build an explanation based on their understanding of the world, rather than to find a formally correct answer or ask an authority figure to provide that answer [2,5,10,25]. Importantly for our work here, framing is highly dynamic and unstablestudents shift between different frames quickly, often on the order of a few minutes at a time $[1,23,25,26]$.

From a cognitive process perspective, sensemaking is a way in which students construct new knowledge by building connections to and within their prior knowledge. When making sense of a new science concept, these connections may be facilitated when students create links between different types of scientific representations for that concept, such as mathematical formalism [1,27], ontological classifications [28-31], graphs and pictorial representations [32-34], and gesture-based representations [35,36]. Mapping techniques like analogies, metaphors, or conceptual blends may also help to facilitate cognitive connections between prior knowledge and new science ideas [20,21,37].

From a discourse perspective, sensemaking is a mode of argumentative dialogue in which students articulate and strengthen explanations, similar to the way in which one articulates and supports a claim in an argument [38-40]. However, researchers have proposed that the goal of sensemaking is to strengthen claims and improve their explanatory power rather than to persuade others or "win" the "argument" [38,39]. As students construct their explanations, they engage in an iterative process of building off of each others' ideas, critiquing those ideas and connections, and (especially in science) describing the mechanisms underlying the phenomena being explained [10,40,41].

Together, these three descriptions provide a thorough characterization of the features of sensemaking - that is, they outline the hallmarks of the process, which one could use to identify it [10]. However, this literature does not show us the trajectory of that process; in other words, even with this body of literature we are still left to wonder how the sensemaking process unfolds in practice. This question presents a problem for researchers interested in studying sensemaking and educators who wish to support it. In order to study and support something we have to know, not just how to recognize it, but also how it behaves - the starting points, ending points, and what happens in between.

To use a related example, in order to support students in physics problem solving, it is not enough to just recognize when students are solving problems or the features of different solution approaches; we also have to understand the complete process of solving a problem, from start to finish. By taking this holistic view, we gain greater perspective on the different approaches students may take, their potential strengths and pitfalls, and their uses in different parts of a physics course. In a similar way, we feel that a full characterization of the sensemaking process would give us greater insight into that process than the hallmarks alone.

In order to study sensemaking in this way, we must draw a theoretical framework that allows us to describe and analyze these types of reasoning processes. In keeping with other studies in PER on student reasoning processes [42-44], we have chosen to use the epistemic games framework.

\section{B. Epistemic games and sensemaking}

Epistemic games (or $e$-games) are a theory designed to describe how people in different fields carry out investigations. The theory was originally proposed by Collins and Ferguson [45] in order to understand how scientists and historians guide their processes of inquiry, but has since been commonly used in the field of physics education research to describe how students and professors approach structured tasks like problem solving [42-44]. As the name suggests, the theory draws an analogy between strategies that people use in investigation and some of the features of games (broadly defined) such as rules, legal moves, and beginning or ending conditions.

Epistemic games have certain key features that define them as a theoretical construct. Each epistemic game has a certain target epistemic form (form of knowledge) that it is meant to produce, and producing this knowledge form is how one completes or "wins" the game. For example, when students play the "answer-making game" [44] their goal is to get the "right answer" to a posed problem. Within this game, the epistemic form (type of knowledge they are trying to produce) is a correct numerical or symbolic answer. Once this answer is found the students complete, and therefore exit, the game.

Epistemic forms are typically constrained in some way, and these constraints help define the rules of the particular epistemic game, i.e., what one is and is not allowed to do. In the above-mentioned answer-making game, we could imagine constraints like the fact that there is only a single right answer, and that this answer has to be expressible in a 
TABLE I. Features of epistemic games.

\begin{tabular}{|c|c|c|}
\hline Feature & Description & Example (from the answer-making $e$-game) \\
\hline $\begin{array}{l}\text { Target epistemic } \\
\text { form }\end{array}$ & $\begin{array}{l}\text { The "goal" or knowledge structure one creates by } \\
\text { "playing" the game }\end{array}$ & $\begin{array}{l}\text { A numeric or symbolic correct answer to a posed } \\
\text { problem }\end{array}$ \\
\hline Constraints & The "rules" of the game & $\begin{array}{l}\text { There is only one right answer } \\
\text { The answer comes in a short, compact form }\end{array}$ \\
\hline Entry conditions & The circumstances that "kick off" the game & $\begin{array}{l}\text { Being assigned a multiple-choice or short answer } \\
\text { physics problem }\end{array}$ \\
\hline Moves & $\begin{array}{l}\text { The most common activities within the game, that help } \\
\text { one to create the target epistemic form }\end{array}$ & $\begin{array}{l}\text { Try to remember the result } \\
\text { Choose and justify an intuitive answer } \\
\text { Do some math }\end{array}$ \\
\hline Transfers & $\begin{array}{l}\text { Moves that change the e-game to another commonly } \\
\text { played e-game }\end{array}$ & Drawing a picture (pictorial analysis $e$-game) \\
\hline
\end{tabular}

short, compact form (a number or equation, rather than a 10-page essay).

Epistemic forms and constraints essentially define the parameters of particular epistemic games. But Collins and Ferguson further argue that $e$-games have three other general characteristics that determine how one actually "plays" the game. These include entry conditions, moves within a game, and opportunities to transfer to another game.

A game's entry condition is the set of circumstances that "kick off" that game. Often an entry condition may be an explicit prompt or question; the answer-making game, for example, seems to be commonly played in response to multiple-choice or short-answer physics problems [44]. However, other games might have a more nebulous set of entry conditions, like an experience, feeling, or perceived need for a tool-for example, Tuminaro and Redish [42] describe the pictorial analysis game, in which students try to create a representation of a physical system (like a circuit diagram) in order to specify the relationships between the elements in that system. Such a game need not be kicked off by a formal prompt or question; instead, the entry condition could be a feeling of puzzlement over how a certain circuit functions.

Moves are the set of actions one is allowed to perform while playing a game. For example, when playing the answer-making game, some possible moves include "try to remember the result," "choose and justify an intuitive answer," and "do some math." Each of these is a possible approach for getting from the entry condition to the target epistemic form, and they may be chained together in various ways; e.g., if a student remembers the result they finish the game in one step, but if they cannot they may have to resort to additional moves [44].

Sometimes certain moves are not allowed in the current game, which may necessitate transferring to another game. For example, a student playing the answer-making game might choose to draw a picture in order to try to justify an intuitive answer. As they are drawing that picture, their task shifts to creating a representation of the system, which constitutes a new epistemic form and thus a new $e$-game (the pictorial analysis game, in fact) with its own set of constraints, entry conditions, moves, and possibilities for transfer. Once the picture is complete, they would then transfer back to the answer-making game and use the picture as a source of additional moves within that game.

For clarity, we summarize these features in Table I.

The epistemic games framework has already been briefly applied to the study of sensemaking in other work focused on physics problem solving. Specifically, Tuminaro and Redish [42] described six $e$-games they observed students playing while solving physics problems, grouping these games under three general categories of student framing: qualitative sensemaking, quantitative sensemaking, and rote equation chasing. Within this analysis, Tuminaro and Redish positioned sensemaking, as we use the term, within a specific frame and epistemic game (the "qualitative sensemaking frame," and "physical mechanism game" respectively). However, their research was not concerned primarily with sensemaking; instead, they focused on how introductory physics students used math when solving tutorial problems. For this reason, the physical mechanism game that they describe is fairly short and cursory-they describe the game as an activity in which "students attempt to construct a physically coherent and descriptive story based on their intuitive sense of physical mechanism" (p. 020101-7), which involves two moves: "build a causal story" and "evaluate story." In this paper we build off of Tuminaro and Redish's work, elaborating on this physical mechanism game and fleshing it out into a more theoretically "thick" description, which we refer to as the sensemaking epistemic game.

How does the epistemic games framework connect to the three above-mentioned theoretical descriptions of sensemaking? We would argue that there is some theoretical overlap (which is to be expected, since all are being applied to the same phenomenon) but that the epistemic games framework can highlight aspects of sensemaking that one might miss by focusing just on framing, dialogue, or 


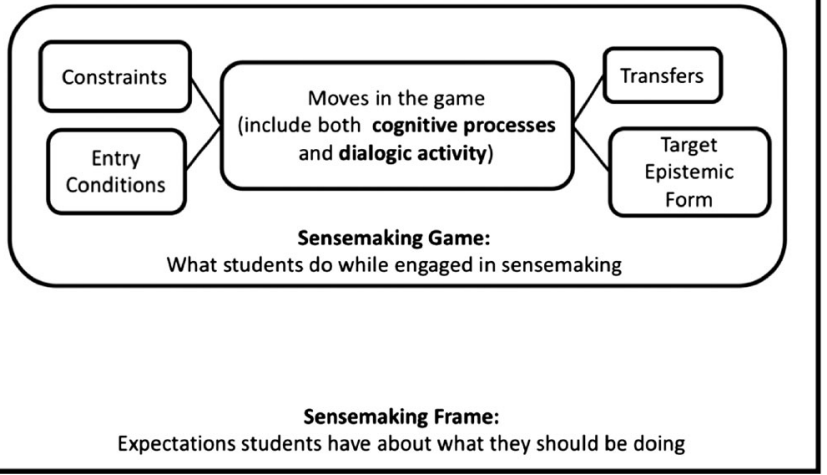

FIG. 1. Theoretical connections between the epistemic games framework and sensemaking framing, dialogue, and cognitive processes.

cognitive processes. For example, frames constitute the set of expectations students bring with them into an activitythat is, do they expect that they should be focused on finding a numerical answer or trying to deepen their understanding of the physical system? E-games, on the other hand, describe the possible actions and boundary conditions of the activity, what students are actually doing. Thus, as Tuminaro and Redish argue, specific $e$-games can be thought of as situated within certain frames [42], and while students are playing a sensemaking game we would also expect them to be in a sensemaking frame.

The $e$-games framework also incorporates features of both student dialogue and strategies for building cognitive connections through the specific moves within particular games. Moves describe the actions students take when playing an epistemic game, and some of these actions may well involve connecting representations, building analogies, and critiquing each other's reasoning. However, the epistemic games framework may also highlight moves that are not captured by the dialogic or cognitive views of sensemaking. Additionally, epistemic games focus not just on what students do while sensemaking but also how they begin and end the process, which are aspects of the phenomenon not addressed by looking at student dialogue or cognitive processes.

We summarize these theoretical connections in Fig. 1.

Based on this theoretical foundation, our primary research questions are as follows:

1. What are the parameters of the sensemaking epistemic game?

2. How does this game progress once it begins?

\section{METHODS: CAPTURING AND ANALYZING SENSEMAKING}

\section{A. Participants and data collection}

In order to understand how sensemaking unfolds, we aimed to compare students' sensemaking processes across multiple groups of students over numerous episodes. The present study featured students from an introductory, algebra-based, undergraduate physics course at a major midwestern university. The course was the second in the algebra-based sequence for nonmajors, focusing on electricity and magnetism.

Based on the features of sensemaking predicted by the research literature (i.e., it is dynamic, requires specific cues to arise, and requires student dialogue), the first author, in consultation with the second author, designed and conducted a series of cognitive clinical interviews $[46,47]$ with students from the course. Clinical interviewing is a flexible methodology in which the interviewer aims to understand and respond to a subject's thinking. The interviewer prepares a set of carefully developed prompts designed to elicit specific aspects of student thinking (in this case, sensemaking or explanation building); however, they are also free to ask new follow-up questions as necessary. This methodology gave us the flexibility to account for the predicted dynamism (i.e., frequent shifts) in student framing by shifting the phrasing and order of questions in order to more reliably cue sensemaking. It also allowed us to ask follow-up questions to pursue sensemaking-rich lines of reasoning. The questions themselves were open-ended and based on phenomena that could be explained using both physics principles and everyday reasoning in order to maximize the number of potential conceptual resources and reasoning strategies students could draw on in their sensemaking.

Building off of the argumentation-based sensemaking literature $[38,39]$, we chose to interview students in pairs in order to encourage dialogue and critiques between the students. During recruitment, we requested that participants find a friend in the class before contacting us to enroll in the study in the hopes that friends would be more comfortable critiquing one another's reasoning. In total we had 9 pairs enroll in the study, collectively consisting of 14 women and 4 men, all white, with 7 same-gender and 2 mixed-gender pairs. Most participants were bioscience majors. We interviewed each pair 5 times throughout the semester, paying each student $\$ 15$ per interview to ensure that they would return. Every pair completed the full set of 5 interviews, except for one pair who were unable to complete the final interview. We video and audio-recorded all interviews, which typically lasted 45 minutes to an hour, resulting in about 42 hours of video data.

Each interview protocol was designed to encourage students to make sense of physical phenomena, either hypothetical (thought experiments) or actual physical demonstrations that they were free to play with. Students were assured that the researchers were only interested in their reasoning, not right or wrong answers. All interviews opened with the interviewer asking students to "talk about what they had been learning in class," both to establish rapport and to prime participants into thinking about recent 
physics concepts (essentially, bringing these concepts to the forefront of their minds). Thereafter, the interviewer would ask various questions related to a phenomenon that could be explained with specific electricity and magnetism concepts such as electric forces, electric fields, electric potential, and current.

The interviews included a range of tasks designed to encourage students to build these explanations, based in part on the extensive literature on the challenging and intriguing nature of electricity and magnetism concepts for introductory physics students, e.g., Refs. [34,48-53]. For example, one of the thought experiments from the electric forces interview used the following prompt:

During a thunderstorm, you and a friend wisely decide to take shelter in your car, which you've parked in an open-air parking lot. As you're waiting, lightning strikes the car. However, besides being a little bit jolted the loud noise and bright flash, you both feel totally fine. After the storm has passed, you feel like getting out to stretch your legs, but your friend yells "Stop!" and warns you not to touch the surface of the car as you get out, because you might still get electrocuted. Do you believe your friend? Why or why not?

Other thought experiments asked them questions like "what would the safest place be to grab an electric eel?" and "is it actually necessary to stand clear from someone when using a defibrillator on them?" In every case, prompts were designed to allow many possible lines of reasoning without any obvious right or wrong answer, but to also require students to make a definitive choice (e.g., step out of the car or not, grab the eel at the head, the middle, or tail, etc.).

Demonstrations included picking up scraps of paper with a charged rod, assembling circuits from lightbulbs and resistors, and investigating interactions between charged pieces of scotch tape. In contrast to the thought experiments, students playing with the demonstrations were typically simply asked to "talk about what you're seeing and what you think it means," with the interviewer asking clarification questions and follow-up questions regarding ideas students brought up.

Throughout the interviews, students were frequently asked to draw representations of what they were imagining was happening, and were provided with large sheets of paper and markers for that purpose. This not only helped students to articulate and clarify their thinking, but also prompted them to create and revise various representations of the phenomena under discussion. The interviewer also deliberately left various props strewn around the table, such as colored stress balls, to be spontaneously picked up and used in explanations. Sometimes the interviewer would himself pick up one of the props and use it to gesture during prompts, normalizing this behavior and priming students to do the same.

\section{B. Data analysis \\ 1. Phase 1: Selecting student groups and reducing the data}

After data collection was completed, the first author reviewed the entire data corpus, in audio form, noting compelling moments that seemed rich in sensemaking. Based on this cursory analysis, he then engaged in repeated intensity sampling [54] in which he pared down the data set to a selection of episodes that seemed to be richest in sensemaking. Here, the goal was not to extract every possible episode of sensemaking from the data set, but rather to get a sample of the episodes that seemed most likely to include sensemaking, which could then be analyzed and compared with one another.

From the full data set, the first author began by choosing two sequences of 5 interviews (10 interviews in total) from the two groups who seemed most prone to sensemaking. He then transcribed all 10 of these interviews in full, creating analytic memos as he did so on the general trajectories of the interviews and episodes or quotes that seemed particularly compelling.

\section{Phase 2: Identifying and analyzing episodes of sensemaking}

Next, the first author reviewed these 10 transcribed interviews and extracted episodes that seemed to have an abundance of the above-mentioned hallmarks of sensemaking. Each interview typically yielded 1 or 2 episodes, 5-15 min in length, for a total of 19 episodes across all 10 interviews. He reviewed these episodes in greater detail, taking additional notes on what happened line by line in order to get a feel for the students' reasoning, and comparing student behavior, gesture, and dialogue to the above-mentioned hallmarks of sensemaking to confirm that they did, in fact, fit with the process described in that literature.

He then reviewed a subset of these episodes a second time, analyzing and coding each utterance in order to highlight relevant differences and similarities in the students' sensemaking processes. This analysis focused on the two most readily observable features of sensemaking from the science education research literature-student framing behaviors and argumentative dialogue, based on the work of Russ et al. [47] and Ford [40]:

1. Framing: Russ et al. [47] proposed three categories of student framing in clinical interviews: oral examination, in which the students' task is to produce a correct answer in a clear and concise fashion; expert interview, in which the students' see their task as discussing their own thinking or prior knowledge on a subject; and inquiry, in which the students' task is to construct an explanation in response to a question posed by the interviewer. However, because the inquiry category did not cover 
TABLE II. Analytic dimensions, categories, and behavioral or discourse markers used in analysis.

\begin{tabular}{|c|c|c|}
\hline Analytic dimension & Category & Behavioral or discourse Markers \\
\hline \multirow[t]{4}{*}{ Framing } & Oral Examination & $\begin{array}{l}\text { Lack of hedging language } \\
\text { Eye contact with interviewer } \\
\text { Limited use of gesture } \\
\text { Use of scientific vocabulary }\end{array}$ \\
\hline & Expert Interview & $\begin{array}{l}\text { Lack of hesitation } \\
\text { Eye contact with interviewer } \\
\text { Frequent gesturing } \\
\text { Use of colloquial terminology }\end{array}$ \\
\hline & Brainstorming & $\begin{array}{l}\text { Long pauses in speech } \\
\text { Restarts during explanation } \\
\text { Little eye contact } \\
\text { Frequent gesturing }\end{array}$ \\
\hline & Sensemaking & $\begin{array}{l}\text { Fluid speech, lack of hesitation or restarts or hedging language } \\
\text { Eye contact (with each other) } \\
\text { Frequent gesturing }\end{array}$ \\
\hline Discourse and argumentation & $\begin{array}{l}\text { Construction } \\
\text { Critique }\end{array}$ & $\begin{array}{l}\text { Students build off or augment each other's explanations } \\
\text { Students question or criticize each other's explanations }\end{array}$ \\
\hline
\end{tabular}

all the cases of explanation building in the data it was split into two subcategories: brainstorming, in which the students are trying to generate an explanation in response to a question by remembering or "dredging up" their prior knowledge on a subject; and sensemaking, in which students are working together to "figure out" an idea that they find new or confusing [22]. Each of these frames had associated behavioral and discourse markers, which are summarized in Table II.

2. Argumentative dialogue: Based on Ford [40], he coded for lines in which students showed signs of argumentation by either engaging in construction (building an explanation) or critique (criticizing or questioning the explanation).

These analytic dimensions, along with their behavioral and dialogic markers, are summarized in Table II.

Using these categories, the first author then looked for patterns across the students' framing and dialogue within the analyzed episodes. With these aspects of the interaction highlighted, it quickly became apparent that these episodes all seemed to unfold in a particular way, with a distinct beginning, middle, and end to students' sensemaking discussions that were accompanied by specific framing and dialogue cues. This structure was strongly reminiscent of the characteristics of the epistemic games framework. So, based on this observation, he coded for key features of epistemic games (entry condition, target epistemic form, moves, transfers) as described by Collins and Ferguson [45] and later used by Tuminaro and Redish [42]. These codes then provided the general parameters of the sensemaking epistemic game.

\section{Phase 3: Selecting and unpacking specific cases}

For the final phase of the analysis, we selected a few specific representative cases to unpack in detail, in order to flesh out the particulars of the sensemaking epistemic game. This approach is both consistent with that used by other epistemic games research in PER [42-44] and is, we feel, suitable for our study goals. Case studies are useful for developing plausible existence arguments and to identify the underlying mechanisms for behavioral phenomena [54,55]; since our focus is on identifying and describing how the sensemaking process can unfold, we feel this methodology is appropriate.

Since we used a case study methodology for our final analysis, we are taking a similar approach in our presentation of the sensemaking game. This presentation is different than that used in other physics education research on epistemic games [42-44]. However, as well as being a faithful presentation of our analysis, we use this approach for two additional reasons: first, the sensemaking epistemic game unfolds over longer timescales than other games in the literature, most of which were sufficiently short that they could be illustrated in a few lines of transcript. For that reason, we feel that a full case description is necessary to see the entirety of the game. Second, unlike most other games in the literature which have a relatively small number of moves, the sensemaking game by its nature has an extremely large number, and we feel that the moves we describe are more compelling when viewed within the narrative structure of the game as a whole.

The episode we present comes from a circuits-based interview (the third in the sequence of 5) with two students, Ruth and Emma (pseudonyms). We chose this particular 
episode because it is "prototypical" of our analyzed episodes, in that it is brief but it illustrates the essential structure of this game (the entry condition and epistemic form), as well as several moves and a brief transfer. Other episodes followed the same basic structure but tended to be longer and have more digressions (and transfers to other epistemic games) interspersed in the discussion.

Ruth and Emma were good friends, and both were biology majors. Both had previously taken the prerequisite algebra-based mechanics course, and Ruth additionally had at least a semester of high school physics. The pair were enthusiastic about discussing and improving their understanding of physics; in this episode, they displayed that enthusiasm during a discussion in which they articulated and resolved a perceived inconsistency in the behavior of parallel circuits.

\section{A CASE OF SENSEMAKING}

\section{A. Setting up for sensemaking}

In general, we have found that the sensemaking game is preceded by some broad discussion of the topic at hand. In this case, that discussion focused on current in series and parallel circuits.

At about $40 \mathrm{~min}$ into the interview, the interviewer had provided Ruth and Emma with a powered circuit board, various resistors and wire segments, several lightbulbs, and a challenge: construct two circuits, one to make a lightbulb shine as brightly as possible and the other to make it shine as dimly as possible while still being visible. As they did this, he asked them to explain their thinking.

To make the bulb shine brightly, Ruth and Emma chose to construct a parallel circuit out of the three lightbulbs provided. Based on this choice, the interviewer asked them to talk about their understanding of the difference between current in a series vs parallel circuit, specifically how the current coming out of the power supply would compare between the two. This prompted Emma to recall Kirchoff's current rule:

342 I: So, what does that say about the current now? Like, if we looked at the current coming right out of this power source before it starts splitting, so what does that say about the current here, with these 3 bulbs like this, versus the current that you had when they were all sort of in one line?

343 E: Yeah, so this \{Emma points at wire coming out of battery\} is $I_{\text {total }}$, and then it's like \{Emma gestures to circuit branches\} $I_{1}, I_{2}, I_{3}$. And $I_{1}$, $I_{2}, I_{3}$ is equal to $I_{\text {total }}$, and then they all become $I_{\text {total }}$ again right before they go in [to the battery].

In response, the interviewer clarified his question, asking the pair to compare the total current in a series circuit to that of a parallel circuit.
344 I: But, I guess I'm asking, like, if you compared $I_{\text {total }}$ now to the $I_{\text {total }}$ you had before in the series circuit, when-

345 E: It should be the same.

At this point, the students have not yet begun sensemaking-they are not trying to "figure something out," focusing, rather, on recalling facts about circuits to answer my interviewing questions. The ease with which they responded, along with the formal terminology they used (such as the $I_{1}, I_{2}, I_{3}$ from Kirchoff's current rule) indicate that they are in the oral exam frame. Their "task," in other words, seems to be to produce clear, concise, correct answers to my posed questions [47].

In the process, however, the students have also assembled (or, more likely, reassembled) a framework of knowledge in response to these interview prompts. That is, the pair have laid out their initial ideas on the phenomenon at hand (parallel circuits), including the notion that current splits and recombines, and that the total current should be the same regardless of the way in which the circuit is constructed. This framework is dynamic, in that it was assembled in the moment and the pair will likely only use it for a short time before moving on to other ideas. However, despite being short lived, we argue that this framework sets them up for sensemaking by both directing their attention to these specific circuit features and giving them a framework within which they can notice a gap or inconsistency in knowledge.

\section{B. Transition into sensemaking}

Next, the students transitioned from assembling a knowledge framework to articulating and addressing a specific inconsistency within that framework. They began by discussing Emma's statement that the current would be the same in parallel and series circuits, trying to decide if that is, in fact, true:

346 R: Well, this is like that question on the, on the homework. It, like, on the quiz last week where it's like 'how do you make it...' (E: Yeah) I mean it, you're dealing with the same... (E: Current, no?) Like, if we have 3 lightbulbs... No, okay, that's not how we said it. Yeah, I think the total current will ultimately be the same? \{whispers\} $V$ equals $I R$...

$347 \mathrm{E}$ : So, is it the voltage that, like, creates the $l$-like, the voltage has a better say on like what the light is than the current? Must be.

348 R: Yeah. The current is just the, the flow. (E: Yeah) Whereas the voltage is what actually makes the light glow.

After some more discussion, the pair tried calculating the net currents in the two types of circuits and found two dramatically different numbers. This result prompted a strong reaction: 
363 R: Oh, that's counterintuitive, yeah.

364 E: Yeah, that sucks. That's super counterintuitive. Why would a current be bigger, just coming out of the volt-out of the battery?

365 R: Because it's the same...

366 E: No, but you know, okay, like, subjectively, there's just, okay, ignore everything past this. \{Emma puts her hand over the circuit\} Coming out of the battery, why wouldn't it be the same current to begin with? In the s-you know what I mean?

Based on their investigation, Emma has noticed an inconsistency in her understanding: batteries send more current through parallel circuits than series circuits, but this behavior feels counterintuitive to her. That is, she seems to feel that power sources should not change their behavior depending on what is attached to them, but their calculations indicate that this is exactly what happens. The pair spent the remainder of the episode looking for some way to resolve this inconsistency.

There is a transition here in the students' dialogue and framing. Initially, during the period when they were discussing and calculating current throughout the different circuits, they seemed to be in a brainstorming frame: the two spoke slowly, hesitantly, staring off into space or at their circuit board. Dialogically, they were building off of or augmenting each others' statements, not critiquing each others' reasoning or answering interviewer questions. Essentially, they seemed to be trying to remember what they knew about series and parallel circuits, "dredging up" knowledge on the subject from sources like homework and quiz questions.

At the point where Emma verbalized her question (line 366), however, we see their dialogue and framing begin to shift: both students become more animated, turn toward each other, make more frequent eye contact, speak more fluidly, and use more gestures, as seen in Fig. 2. Their hesitancy drops away. Rather than simply building off of each other's ideas, their dialogue starts to become more argumentative (as we see from Emma's critique in line 366). Their task also seems to shift, from trying to remember what they know about circuits to trying to resolve the inconsistency Emma pointed out. This goal, of building an explanation based on one's understanding of the world is consistent with that described in the sensemaking literature $[2,5,10,25]$. Additionally, the critical shift in the pair's dialogue is consistent with the argumentative nature of sensemaking $[38,40]$. So, this transition, we argue, marks the students' entry into a sensemaking frame.

As we will show in the next section, the pair's shift goes beyond just framing behaviors: Emma and Ruth have also, we claim, begun playing the sensemaking epistemic game. Since this transition occurs around the moment when Emma articulates her question in line 366, we consider this question to be the entry condition into the game.

\section{Playing the sensemaking game}

Having transitioned into a sensemaking frame and entered into the sensemaking game, the students now began to build an explanation to resolve this inconsistency. The episode continued as Ruth responded to Emma's question, "why wouldn't it be the same current to begin with?":

367 R: Because here the resistance is smaller. Because the equivalent resistance is, is 1 over four plus four plus fou-whatever we said that each resis-three plus three plus three. And so, since, or it's like a third plus a third plus a third.

368 E: But then it's one over that number.

369 R: But then, exactly, but that number is still smaller than the resistance when they're in series with each other.

370 E: I know, but what I'm saying is like if you just have a circuit, \{Emma draws a small circuit $\}$ the current coming out right away, right? \{Emma draws an arrow coming out of the battery\} Before you're looking at anything here, whether it's parallel or in series, why wouldn't that current be the same?

371 R: Because there's less resistance-

372 E: But it hasn't approached the resistance yet.

373 R: But I think it just knows.

$374 \mathbf{E}$ : It just knows?
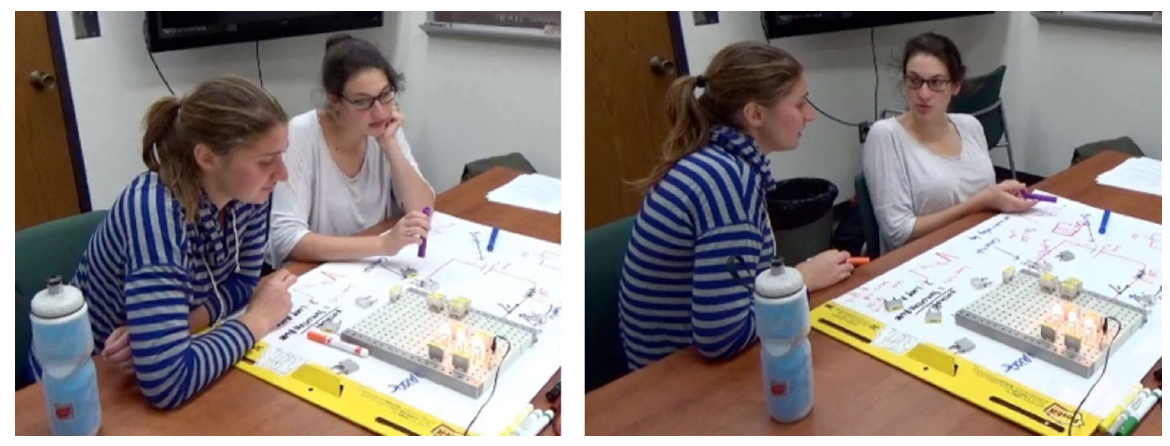

FIG. 2. Student body position and gaze before (left) and after (right) the frame shift. 
Here, Ruth and Emma are in the midst of playing the sensemaking game. Looking at the structure of their conversation, the pair are now engaged in a cyclical process of iteratively building an explanation that resolves Emma's inconsistency.

This explanation, we propose, is the epistemic form of the sensemaking game, the end-product that the pair are trying to produce. But Emma is not satisfied with just any explanation-she seems to have certain requirements, certain points the explanation has to address, as we see from her reactions in lines 370 and 374. Mathematical arguments seem to be insufficient for her, as are teleological explanations ("It just knows"). As each argument or explanation is rejected, Emma returns to her question, which drives the pair into their next cycle of construction and critique.

Ruth and Emma's behavior and body language in this segment remain consistent with the sensemaking framing behaviors described above. The pair are animated, making eye contact with each other, with gestures and turns of talk coming in quick succession. Their dialogue has also fully shifted into the cycles of construction and critique which researchers have argued is characteristic of sensemaking $[38,40]$. From a framing perspective, their task or goal seems to be to build an explanation that achieves coherence [6] between what Emma thinks should be true (batteries cannot "know" how much current they should send to the circuit) and what they have observed.

In this segment, we also see several moves from the sensemaking game, recurring tactics that the students use to get one step closer to the target epistemic form. In line 367, we see Ruth assigning values to illustrate her point that the equivalent resistance is smaller. While she could have just left her argument at "the equivalent resistance is smaller," she goes one step further and actually assigns numbers to that resistance to flesh out her claim. In line 370 we see Emma refining her question in response to Ruth's proposed solution, setting up her critique in line 372 that the equivalent resistance shouldn't play a role because the current coming out of the battery has not "approached" this resistance.

Since the pair had not yet provided a satisfactory resolution to Emma's inconsistency, the discussion continued with Ruth elaborating on her claim that the battery "just knows":

375 R: It kno-like it, it's like, this voltage is stuck, and so it can't change how many volts are being put out, so the only-and it can't change what resistors are out and what orientation. So it can only change this current. It can only decide how fa-er, how, yeah, how much it, charge can move in,

376 E: Right, I understand that, once it [the current] gets to like this node. \{Emma points to the first junction\} But I don't get how it [the battery] would know what's coming [further down the circuit] from here. You know what I'm saying?

Here, again, we see Emma refining her question (line 376). This refinement was a consistent pattern across the episode; even as the pair tried to address the inconsistency mathematically ("the equivalent resistance is..."), teleologically ("it just knows"), and (in the next segment) mechanistically, they continually returned to Emma's question, which acted as the starting point for each cycle of dialogue. This, we posit, is evidence that the initial question was more than just an entry condition into the sensemaking game: it also acted as a recurring move throughout the game, which Emma successfully used to critique Ruth's explanations.

\section{Resolving the inconsistency}

After playing the sensemaking game for several minutes, the pair had yet to resolve Emma's inconsistency. So, what was Emma looking for? The discussion continued:

377 R: I think it's just that charges are everywhere. But no, I, I see what you're saying, but I also don't think we're seeing it from that perspective.

378 E: Yeah, I guess I'm also, yeah, I guess I'm also thinking about it as, like, the charge starts right here, but really it's like always all moving. Yeah.

Here, Emma seemed to be signaling that Ruth's explanation resolved her inconsistency. To confirm this hypothesis, the interviewer pressed them to explain what they had established:

379 I: So, could you say more about that? Like, uh, Ruth, you said like there's charge everywhere here. So how would that-

380 R: Well, like, if we think about it, we don't have, like, when we have a circuit put together, and the minute we put the lightbulb in, it turns \{snaps fingers\} on. Like, er, that, that, immediately after we put the lightbulb in, it turns on, so it's not like 'oh, it's [the current] starting from here, and then it's going - and once it gets here then it'll turn it on and keep moving.' It's the fact that because this wire is connected, there's charges all over, and so even though they're, the current is what's driving the charge around, there's already charge built up in here, so by the time I put it in, that, it starts everything moving. So the second everything starts moving, I'm gonna get, there's gonna be things moving here, here, here, everywhere.

381 E: Yeah. That's what I was missing. Is that, like, I can't think of this as independent from everything else. 'Cause it's already going, so it's like, it's not that this charge doesn't know about this charge already, it's just that these charges have alr-like, it's going so fast that this charge is already going. 

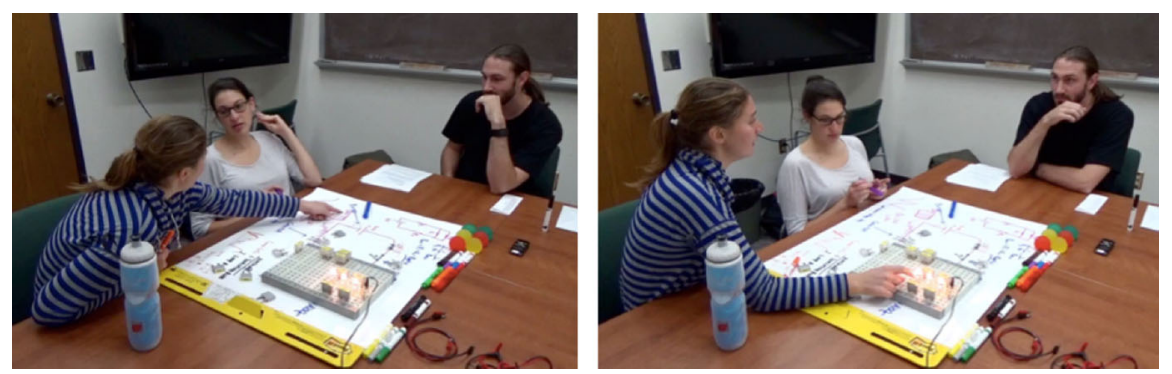

FIG. 3. Student body position and gaze in the sensemaking frame (left) vs the expert interview frame (right).

Based on this elaboration and Emma's explicit statement "that's what I was missing," it seems that Emma was looking for a mechanistic explanation [41] that would align their mathematical results her intuitive understanding of circuits (batteries cannot "tell" what they are hooked up to). For her, the notion that "charges are everywhere" throughout the circuit made that connection, achieving coherence and filling in what she was "missing." This explanation, then, was the epistemic form she was looking for, and once they had constructed it they completed the sensemaking game.

The pair's framing cues during this segment confirm that they had finished the sensemaking game. Where before they were addressing each other, exchanging quick bursts of dialogue, Ruth now turned to the interviewer and spoke authoritatively, explaining the conclusion they had come to, as shown in Fig. 3. Emma, building on Ruth's summary, added her explicit confirmation that she was satisfied with this explanation. Based on these summaries, the pair seem to have shifted to what Russ et al. called the expert interview frame in which their goal or task was to transmit the knowledge they had constructed to the interviewer.

\section{THE SENSEMAKING EPISTEMIC GAME DESCRIBED}

Building on this case study, we can now begin to unpack the features of the sensemaking epistemic game. To do so, we first outline the trajectory of the game- how it unfolds in general terms - and then flesh out this description with the individual characteristics of the game drawn from both Ruth and Emma's case and other relevant cases in our data corpus.

\section{A. Trajectory of the sensemaking epistemic game}

Looking at the episode as a whole, we can see that Ruth and Emma's sensemaking unfolded in a distinct way, which we summarize in Fig. 4:

This process, we propose, proceeds in four stages, corresponding to the four sections of the case study presented above. Below, we summarize the features of these four stages and supplement them with data from other analyzed cases:
Step 0, Assembling a knowledge framework: Before sensemaking begins, students assemble an initial knowledge framework, drawing on and priming their prior knowledge on a particular subject. This knowledge framework is dynamic, in that it is assembled (or reassembled) in the moment in response to contextual cues, like a prompt or question posed by the interviewer. For example, in other interviews students began by discussing their general understanding of topics like voltage drop in circuits, electric fields around charges, or their everyday experiences with static electricity while doing laundry. This process of activation is a necessary precursor to sensemaking, in that the students are unlikely to notice a gap or inconsistency in their understanding until they have assembled said framework.

Step 1, Noticing a gap or inconsistency: Next, as they are assembling this framework, one of the students notices an inconsistency or gap in their knowledge. In the case above, this happened in line 366, when Emma articulated her question "Coming out of the battery, why wouldn't it be the same current to begin with?" In other cases, students articulated gaps in knowledge with statements like "I don't know if I fully understand it [Voltage], though," or "I don't know how you'd get rid of this charge, then." These questions precipitate the shift into a sensemaking frame and thus act as the entry condition to the sensemaking epistemic game.

Step 2, Generating an explanation: Once a student has identified a gap or inconsistency, they begin to iteratively build and rebuild an explanation to resolve the inconsistency or bridge the gap. During this period of explanation building, the students in our data corpus would exhibit many of the characteristics of sensemaking described above, such as cycles of construction and critique [40],

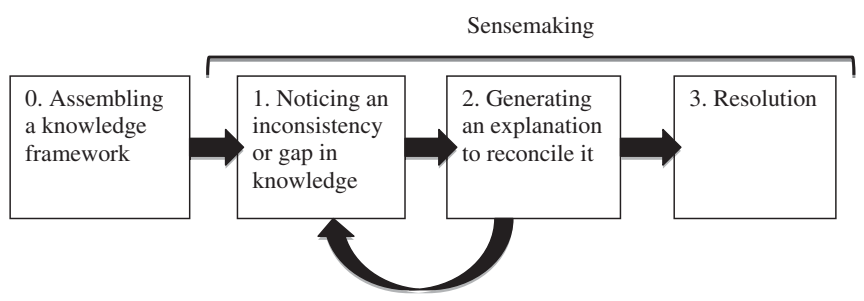

FIG. 4. Students' trajectory through the process of sensemaking. 
mechanistic reasoning [10,41], mapping across different representations [1,34,56,57], and analogy building [21,58]. For example, one pair of students explained voltage drops in parallel circuits by constructing a graph of the voltage drops around the circuit, then connecting it to the features of an equipotential map. In another case, Ruth and Emma spent much of their time discussing the similarities between a car that had been struck by lightning and precipitation static on airplanes.

Step 3, Resolution: During the final step, students will sometimes successfully build an explanation that resolves this gap or inconsistency. For example, one pair were able to resolve a question about the safety of being in a car struck by lightning by proposing rain runoff as a mechanism for grounding away the excess charge. Other times they give up out of frustration or exhaustion. For instance, in another interview Ruth and Emma were unable to come to any agreement on the safety of leaving a car after it had been struck by lightning (because they were unable to decide if the excess charge could leave the car) and so decided to "agree to disagree." Either way, the sensemaking game ends, and the students move on to further sensemaking or other activities.

This model allows us to describe the general trajectory of sensemaking. However, it does not help us define the "rules" or characteristics of the game that actually drive the process. So, to flesh out this description we now use the epistemic games framework to flesh out the parameters of the game.

\section{B. Parameters of the sensemaking epistemic game 1. Entry conditions and epistemic form}

The first articulation of a particular gap or inconsistency in knowledge acts as the entry condition into the sensemaking $e$-game. In the case presented above, we see evidence of this in the frame shift that happens before or after the initial articulation of Emma's inconsistency, when the pair shift from brainstorming to sensemaking. This shift marks the transition between the students' initial discussion and the actual "game" of sensemaking and was consistent across all of the analyzed examples of sensemaking. The epistemic form, or goal, of the game is then an explanation that resolves the inconsistency.

\section{Moves}

The sensemaking game has certain moves that seem common across our analyzed groups. Since the goal of the game is to build an explanation, these moves are intended to advance the explanation by drawing on knowledge from a variety of sources and/or critiquing aspects of the explanation. For example, in our presented case Emma repeatedly refined her question, thereby narrowing the scope of the explanation, and Ruth at one point assigned values to a mathematical argument in order to illustrate her point.
Because of the brevity of the case above, as well as the abstractness of the topic, we were only able to identify these two moves from that case; however, in addition to these two moves, we have gathered illustrative examples of five other moves commonly seen in our data corpus in Table III:

To be clear, these were just some of the recurring moves we observed in our recorded instances of the sensemaking game. This is not an exhaustive list- there will certainly be additional moves in this game, used by other students playing the game in different settings. Our goal here is not to catalogue all of the possible moves of the sensemaking game; rather, we are simply trying to illustrate the types of moves that students may use when playing this game.

Other epistemic games analyses outline the particular order in which their moves are used [42-44]. However, the sensemaking game is less prescriptive than $e$-games focused on mathematical problem solving, in which students are proceeding towards a single correct answer. When building explanations, there are a wide variety of conclusions students can come to and an even wider variety of approaches students can take, since there are many different bodies of knowledge they can draw on to build those explanations. In practice, this meant that no two groups ever used the same set of moves, even when they had identified similar inconsistencies in knowledge. Therefore, we see little reason in trying to directly map the order in which students used these moves.

\section{Constraints}

Identifying constraints presents a major analytical difficulty: how do you determine what is not allowed in a game? This difficulty is perhaps why none of the other studies of epistemic games in the literature discuss the constraints of the games they present.

The easiest way to figure out when something is a "rule" is to look for cases in which that rule is broken; so, ideally, one would look for cases in which students started sensemaking and then ended prematurely, and then examine the factors that caused that premature end. However, this kind of analysis was outside of the scope of our study: we were focused on collecting and characterizing as many positive instances of sensemaking as possible, and so we were not specifically looking for cases in which sensemaking ended prematurely (that is, before students had even begun to substantively build their explanations). Therefore, it was not possible to look for the constraints or boundaries of sensemaking, since all of our examples stayed within those boundaries.

Although we do not have direct evidence of constraint violation, we can speculate at some of the constraints based on the descriptions and characterizations of sensemaking in the science education literature. In other words, we can use the already-existing theories of sensemaking to predict some of its boundary conditions. These constraints, we propose, might represent some of the "rules" of 
TABLE III. Moves from the sensemaking epistemic game.

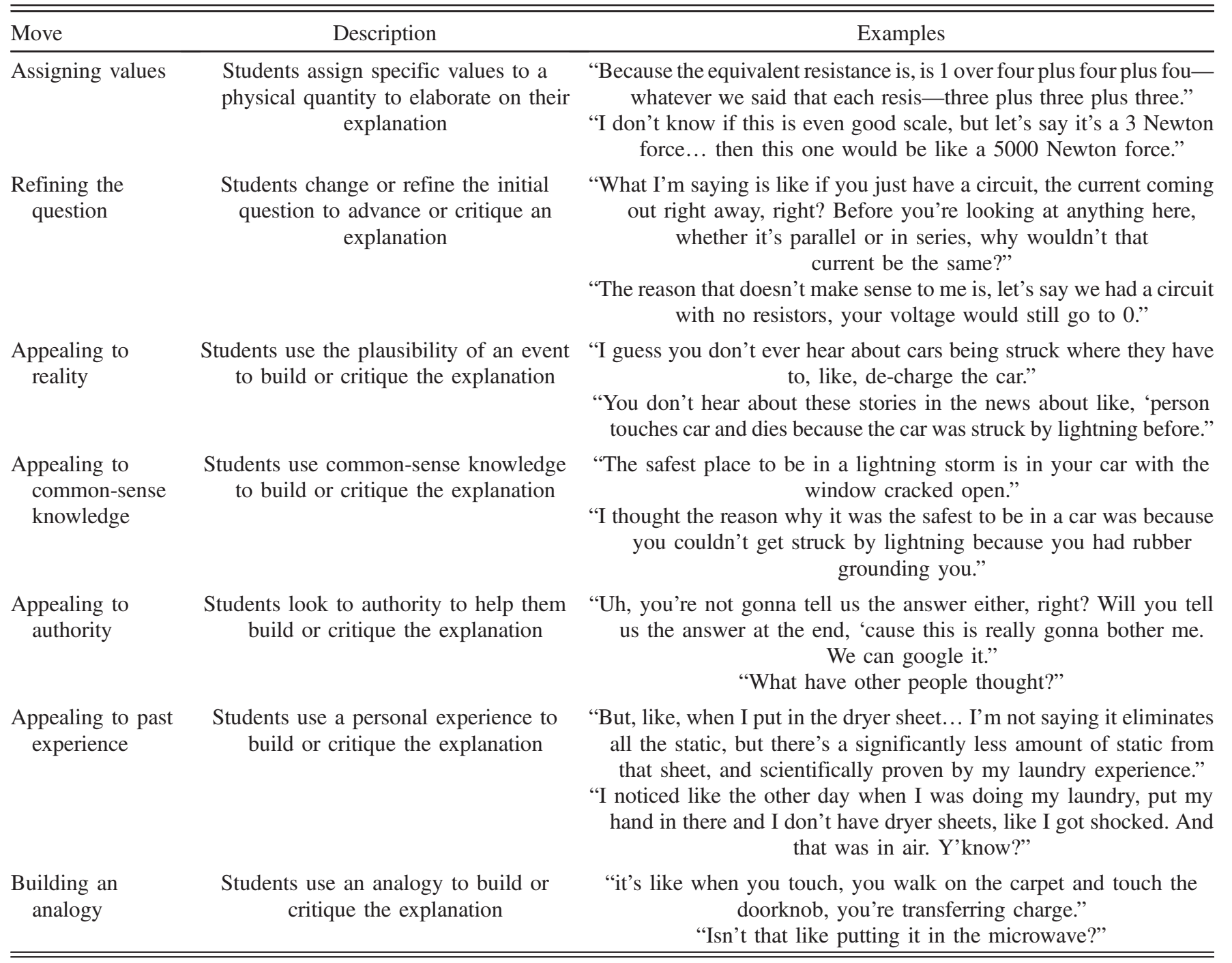

sensemaking - if they are violated, we would hypothesize that the activity in question is either not sensemaking (i.e., some other activity like answer making) or, if that violation happens during the game, it might bring a premature end to the game.

1. Sensemaking is a discussion in which students contribute their ideas. Sensemaking is not a lecture, or a one-way transfer of information $[2,5,38,40]$. Thus, one constraint on sensemaking is that it must be a two-way discussion, and the game would end if one student completely takes over the conversation, turning it into a monologue.

2. Sensemaking happens around a topic or idea that one has not already made sense of yet [57]. Thus, the sensemaking game would end (or, perhaps never start at all) if it is on a topic one participant already feels completely knowledgeable about, since that would suppress critique of the explanation being built [40].
3. Sensemaking involves colloquial talk or definitions, not just formal terminology [2,25]. Thus, the sensemaking game would end if students simply revert to citing formal definitions, rather than discussing their own ideas.

Again, we are not claiming that this list of constraints is exhaustive, nor that it necessarily covers all of the possible variations for this game. Different students and different groups had different approaches to the sensemaking game, and although there were patterns across the groups we examined, there are almost certainly other constraints students might impose when playing this game. However, we feel that this limited number of constraints and moves is acceptable for our initial description of the game, since our purpose is more to use this theoretical machinery to describe the general parameters of the activity - the ways students get in and stay in the sensemaking game-than to specify the ways they proceed while they are playing it (the moves they make). 


\section{Exit conditions}

If the students successfully construct an explanation that resolves the perceived gap or inconsistency in knowledge to the satisfaction of the participants then the game is over-sense has been made. It is difficult to tell a priori, however, what will be deemed as a satisfactory explanation, since this seems to be different for each student and question. Some authors have suggested students make these types of evaluations based on their perception of the explanation's simplicity, general explanatory power, or its coherence with ideas that they hold in high regard [10,59]. However, because such criteria are strongly tied to each individual student we were not able to discern any underlying patterns. That is, in these episodes sometimes a physical mechanism (rain, charges throughout a circuit) sufficed; other times, students resolved the inconsistency after constructing an analogy (voltage drops are like "hills" for charges) or performing a physical experiment (picking up pieces of paper with a charged rod).

It is similarly difficult to predict when or why students will choose to give up on the sensemaking game before they have actually done so. Sometimes students seemed to become frustrated after repeated unsuccessful bids to generate a satisfactory explanation. In these cases, the interviewer would often wait until student dialogue had slowed down or stopped (as measured by long, multisecond silences) before trying to prod the students to continue with follow-up questions. If they were unwilling to continue he would then move on to the next prompt, leaving the game unfinished. At other times, students might simply lose interest in their original question and explicitly signal their wish to move on by asking the interviewer to provide the answer or shifting to a different discussion topic. However, these cases were again individual to the students and topic, and it was difficult to discern any cross-cutting patterns.

\section{DISCUSSION: USEFULNESS OF THE EPISTEMIC GAMES DESCRPTION}

What does this description of sensemaking buy us? We argue that an epistemic games-based description of sensemaking has several advantages over either a theoretical definition of sensemaking or a list of the hallmarks of the process. First, it emphasizes that sensemaking is not just a nebulous type of reasoning or "way of thinking"-instead, sensemaking is a separable, defined activity, with boundaries and transitions that can be analytically identified. From an $e$-games perspective, sensemaking is a distinct approach to knowledge construction, with its own goal and rules.

Second, and relatedly, this description allows us to distinguish sensemaking from other processes and practices in science education. For example, explanation building is one of the key practices of the NGSS framework [60], and as illustrated in the case above, sensemaking involves a great deal of explanation building. Does that mean the two are one and the same? In other words, if we want our students to engage in sensemaking, is it sufficient to simply encourage them to explain physical phenomena, as the NGSS recommends?

Based on this epistemic games description of sensemaking, we would argue no. Although sensemaking involves explanation building, the type of explanation matters, as does the student motivation for building the explanation. To be playing the sensemaking game, the students' explanations need to have both the target epistemic form and the entry condition associated with that game. In other words, the sensemaking game is used to construct understanding, to make new conceptual connections; explanations can serve not only this function, but also many others, like describing or illustrating a concept one already understands.

However, although we see sensemaking as a vehicle for building new knowledge, we also wish to be cautious in our estimation of the strength, scale, or endurance of the new conceptual connections formed while sensemaking. Sensemaking is described in the science education research literature as a dynamic process $[1,2,25]$ - that is, it takes place over short time periods (Ruth and Emma's case took a little over $7 \mathrm{~min}$ in total) and students may or may not reassemble these same conceptual connections during subsequent conversations. This is not to say the process is not valuable; rather, it suggests that students may have to engage in consistent, repeated sensemaking over a long period of time to build larger-scale, more stable cognitive connections.

\section{CONCLUSION AND IMPLICATIONS}

To summarize, we are proposing a model for the sensemaking process in which students assemble an initial knowledge framework, identify a gap or inconsistency in that framework, iteratively build an explanation to resolve the gap or inconsistency, and (hopefully) arrive at a resolution. Along the way, there are numerous moves the students can use to construct the explanation, as well as constraints or rules that regulate the process.

To be clear, ours is an initial description of this game, based on a limited set of episodes in an introductory physics context. We mean it to be a foundation on which others can build future studies to flesh out the details of the game, based on other examples and contexts. However, even in its present form we can use it to glean insights on how learning environments can support sensemaking and how researchers might elicit and analyze sensemaking in future studies.

There has already been some research on the features of sensemaking-focused learning environments. Turpen and Finkelstein [61], in their investigation of clicker question use during peer instruction, observed that a classroom 
focused on sensemaking has the following norms: lowstakes grading practices; an instructor who consistently and explicitly emphasizes sensemaking or reasoning; significant opportunities for students to build explanations and discuss physical reasoning in small-group formats and whole-class discussions; and frequent opportunities for the instructor to model scientific discourse (p. 020123-16).

Our description of sensemaking builds on this research by providing a framework to understand why these norms work. Based on our model, we argue that each norm is meant, in some way, to help guide students through the different steps of the sensemaking process. Clicker questions provide students with initial prompts, which prime them to assemble their initial knowledge frameworks. When they notice gaps or inconsistencies in these frameworks, the low stakes grading practices give students the time, space, and permission to pursue and resolve them. The remaining norms (focus on explanation building, opportunities for discussion of physical reasoning, and modeling of scientific discourse) then explicitly support students in building their explanations.

Turpen and Finkelstein derived these norms from observations of classrooms that happened to support sensemaking; with our model of sensemaking, however, we can go one step further and propose more specific, targeted suggestions for how to engineer learning environments to support the process. For example, we predict that sensemaking-focused prompts will be most effective if they are open-ended and explainable from multiple conceptual angles; for example, a question like "if you charge up a capacitor, then disconnect it from a circuit and pull apart the plates, the voltage increases. Why does this happen?" can be explained in multiple ways (using the mathematical definition of capacitance, conservation of energy, electric fields, or a "height" analogy for voltage). These multiple explanatory paths give students room to articulate and address inconsistencies between the different approaches. One might even explicitly encourage students to consider the different paths to the answer by asking a follow up question like "how many different ways can you explain this behavior? Are they all coherent with one another?"

Additionally, with regard to the entry condition to the sensemaking game, we have noticed that students must engage in a certain amount of metacognitive reflection to pin down and articulate their gaps or inconsistencies in knowledge. So, instructors who wish to support the sensemaking game may want to explicitly address and encourage this kind of metacognitive practice in their courses.

Beyond specific guidelines for learning environments, we can also use this model to situate sensemaking within the science education curricular ecology - that is, we can use it to decide where to best leverage sensemaking in a course. Based on our observations, sensemaking is a process that is especially useful for helping students "debug" or "defragment" knowledge they have already gained, as Emma and Ruth did in the case presented above. This means that to help students make sense of specific physics concepts, we may want to engineer our courses to "nudge" students towards sensemaking after have already encountered said concepts at least once (e.g., from a prelecture video or during a whole-class meeting).

For researchers, these guidelines on supporting sensemaking in the classroom may also apply when eliciting sensemaking in more controlled environments like interviews. However, this model additionally provides both suggestions and open questions for future sensemaking research. For example, if the sensemaking game does, indeed, begin with a gap or inconsistency in knowledge, this raises the question of what kinds of gaps or inconsistencies are most effective at kicking off sensemaking? While students are in the midst of the game, what other moves might they use? Are particular moves used more often than others, and which other epistemic games do students commonly transfer to while they are sensemaking? Additionally, how do students' backgrounds (either cultural or academic) affect their particular instances of the sensemaking game? The students in our population were relatively homogeneous, but researchers from science education have argued that students, especially those from nondominant backgrounds, may draw on their familial or cultural ways of knowing when sensemaking $[62,63]$. So, we are left to wonder how this game might be played in other cultures, contexts, and institutions.

At the other end of the spectrum, researchers might study the factors that contribute to successful or unsuccessful resolution of the sensemaking game. For example, in cases where students have successfully completed the game researchers may investigate which types of explanations students found most effective for resolution. Emma, in the case above, seemed to be looking for a mechanistic explanation rather than a mathematical one-was this preference unusual, or is it common across students? For students who do not successfully complete the game, what factors led them to end it prematurely? Are there specific contextual or social cues that might encourage students to give up? With a better understanding of the different ways sensemaking can end, perhaps such research could put forward strategies for keeping students engaged in the sensemaking frame.

In conclusion, we believe that sensemaking holds great promise as a design principle for physics education. However, to unlock that potential, we must characterize the process-not just in descriptive terms, but also establishing how and why it happens. In this study, we have taken a first step in documenting the process, beginning to end, and teasing out some of the factors that drive it. We look forward to seeing the ways in which this theory will be further refined, how it may be built into physics curricula, and the many interesting explanations students will generate as they are sensemaking. 
[1] A. Gupta and A. Elby, Beyond epistemological deficits: Dynamic explanations of engineering students' difficulties with mathematical sense-making, Int. J. Sci. Educ. 33, 2463 (2011).

[2] P. Hutchison and D. Hammer, Attending to student epistemological framing in a science classroom, Sci. Educ. 94, 506 (2010).

[3] E. Gire, C. Manogue, N. S. Rebello, P. V. Engelhardt, and C. Singh, Making sense of quantum operators, eigenstates and quantum measurements, AIP Conf. Proc. 1413, 195 (2012).

[4] D. Hammer, Two approaches to learning physics, Phys. Teach. 27, 664 (1989).

[5] B.a. Danielak, A. Gupta, and A. Elby, Marginalized identities of sense-makers: Reframing engineering student retention, J. Eng. Educ. 103, 8 (2014).

[6] T.-R. Sikorski and D. Hammer, Looking for coherence in science curriculum, Sci. Educ. 101, 929 (2017).

[7] E. Redish, J. Saul, and R. Steinberg, Student expectations in introductory physics, Am. J. Phys. 66, 212 (1998).

[8] W. K. Adams, K. K. Perkins, N. S. Podolefsky, M. Dubson, N. D. Finkelstein, and C. E. Wieman, New instrument for measuring student beliefs about physics and learning physics: The colorado learning attitudes about science survey, Phys. Rev. ST Phys. Educ. Res. 2, 010101 (2006).

[9] T. J. Bing and E. F. Redish, Epistemic complexity and the journeyman-expert transition, Phys. Rev. ST Phys. Educ. Res. 8, 010105 (2012).

[10] S. Kapon, Unpacking sensemaking, Sci. Educ. 101, 165 (2017).

[11] A. Karelina and E. Etkina, Acting like a physicist: Student approach study to experimental design, Phys. Rev. ST Phys. Educ. Res. 3, 020106 (2007).

[12] E. Etkina, A. Karelina, and M. Ruibal-Villasenor, How long does it take? A study of student acquisition of scientific abilities, Phys. Rev. ST Phys. Educ. Res. 4, 020108 (2008).

[13] E. F. Redish, J. M. Saul, and R. N. Steinberg, On the effectiveness of active-engagement microcomputer-based laboratories, Am. J. Phys. 65, 45 (1997).

[14] W. Potter, D. Webb, C. Paul, E. West, M. Bowen, B. Weiss, L. Coleman, and C. De Leone, Sixteen years of collaborative learning through active sense-making in physics (CLASP) at UC Davis, Am. J. Phys. 82, 153 (2014).

[15] A. Elby, Helping physics students learn how to learn, Am. J. Phys. 69, S54 (2001).

[16] D. Hammer and A. Elby, Tapping epistemological resources for learning physics, J. Learn. Sci. 12, 53 (2003).

[17] E. Brewe, L. Kramer, and G. O'Brien, Modeling instruction: Positive attitudinal shifts in introductory physics measured with CLASS, Phys. Rev. ST Phys. Educ. Res. 5, 013102 (2009).

[18] E. Brewe, Modeling theory applied: Modeling instruction in introductory physics, Am. J. Phys. 76, 1155 (2008).

[19] R. Chabay and B. Sherwood, Matter and Interactions, 4th ed. (John Wiley \& Sons, Hoboken, NJ, 2011).

[20] J. Clement, Using bridging analogies and anchoring intuitions to deal with students' preconceptions in physics, J. Res. Sci. Teach. 30, 1241 (1993).
[21] N. S. Podolefsky and N. D. Finkelstein, Analogical scaffolding and the learning of abstract ideas in physics: An example from electromagnetic waves, Phys. Rev. ST Phys. Educ. Res. 3, 010109 (2007).

[22] T. O. B. Odden and R.S. Russ, Defining sensemaking: Bringing clarity to a fragmented theoretical construct, Sci. Educ. (to be published).

[23] R. E. Scherr and D. Hammer, Student behavior and epistemological framing: Examples from collaborative active-learning activities in physics, Cognit. Instr. 27, 147 (2009).

[24] D. Tannen, Framing in Discourse (Oxford University Press on Demand, New York, 1993).

[25] S. Rosenberg, D. Hammer, and J. Phelan, Multiple epistemological coherences in an eighth-grade discussion of the rock cycle, J. Learn. Sci. 15, 261 (2006).

[26] B. W. Frank and R. E. Scherr, Interactional processes for stabilizing conceptual coherences in physics, Phys. Rev. ST Phys. Educ. Res. 8, 020101 (2012).

[27] B. L. Sherin, Common sense clarified: The role of intuitive knowledge in physics problem solving, J. Res. Sci. Teach. 43, 535 (2006).

[28] A. Gupta, A. Elby, and L. D. Conlin, How substance-based ontologies for gravity can be productive: A case study, Phys. Rev. ST Phys. Educ. Res. 10, 010113 (2014).

[29] B. W. Dreyfus, B. D. Geller, J. Gouvea, V. Sawtelle, C. Turpen, and E.F. Redish, Ontological metaphors for negative energy in an interdisciplinary context, Phys. Rev. ST Phys. Educ. Res. 10, 020108 (2014).

[30] A. Gupta, D. Hammer, and E. F. Redish, The case for dynamic models of learners' ontologies in physics, J. Learn. Sci. 19, 285 (2010).

[31] M. T. H. Chi and J. D. Slotta, The ontological coherence of intuitive physics, Cognit. Instr. 10, 249 (1993).

[32] W. M. Christensen and J. R. Thompson, Investigating graphical representations of slope and derivative without a physics context, Phys. Rev. ST Phys. Educ. Res. 8, 023101 (2012).

[33] L. Ivanjek, A. Susac, M. Planinic, A. Andrasevic, and Z. Milin-Sipus, Student reasoning about graphs in different contexts, Phys. Rev. Phys. Educ. Res. 12, 010106 (2016).

[34] E. Gire and E. Price, Arrows as anchors: An analysis of the material features of electric field vector arrows, Phys. Rev. ST Phys. Educ. Res. 10, 020112 (2014).

[35] C. A. Manogue, E. Gire, and D. J. Roundy, Tangible metaphors, Proceedings of the Physics Education Research Conference 2013, Portland, OR (AIP, New York, 2014), p. 27.

[36] R. E. Scherr, H. G. Close, S. B. McKagan, and S. Vokos, Representing energy. I. Representing a substance ontology for energy, Phys. Rev. ST Phys. Educ. Res. 8, 020114 (2012).

[37] E. Brewe, Energy as a substancelike quantity that flows: Theoretical considerations and pedagogical consequences, Phys. Rev. ST Phys. Educ. Res. 7, 020106 (2011).

[38] L. K. Berland and B. J. Reiser, Making sense of argumentation and explanation, Sci. Educ. 93, 26 (2009).

[39] L. K. Berland and B. J. Reiser, Classroom communities' adaptations of the practice of scientific argumentation, Sci. Educ. 95, 191 (2011). 
[40] M. J. Ford, A dialogic account of sense-making in scientific argumentation and reasoning, Cognit. Instr. 30, 207 (2012).

[41] R. S. Russ, R. E. Scherr, D. Hammer, and J. Mikeska, Recognizing mechanistic reasoning in student scientific inquiry: A framework for discourse analysis developed from philosophy of science, Sci. Educ. 92, 499 (2008).

[42] J. Tuminaro and E. Redish, Elements of a cognitive model of physics problem solving: Epistemic games, Phys. Rev. ST Phys. Educ. Res. 3, 020101 (2007).

[43] M. Kustusch, D. Roundy, T. Dray, and C. Manogue, Partial derivative games in thermodynamics: A cognitive task analysis, Phys. Rev. ST Phys. Educ. Res. 10, 010101 (2014).

[44] Y. Chen, P. W. Irving, and E. C. Sayre, Epistemic game for answer making in learning about hydrostatics, Phys. Rev. ST Phys. Educ. Res. 9, 010108 (2013).

[45] A. Collins and W. Ferguson, Epistemic forms and epistemic games: Structures and strategies to guide inquiry, Educ. Psychol. 28, 25 (1993).

[46] H. Ginsburg, The clinical interview in psychological research on mathematical thinking: Aims, rationales, techniques, Learn. Math. 1, 4 (1981).

[47] R. S. Russ, V. R. Lee, and B. L. Sherin, Framing in cognitive clinical interviews about intuitive science knowledge: Dynamic student understandings of the discourse interaction, Sci. Educ. 96, 573 (2012).

[48] L. Viennot and S. Rainson, Students' reasoning about the superposition of electric fields, Int. J. Sci. Educ. 14, 475 (1992).

[49] C. Guruswamy, M. D. Somers, and R. G. Hussey, Students' understanding of the transfer of charge between conductors, Phys. Educ. 32, 91 (1997).

[50] C. Furió and J. Guisasola, Difficulties in learning the concept of electric field, Sci. Educ. 82, 511 (1998).

[51] P. Licht, Teaching electrical energy, voltage and current: An alternative approach, Phys. Educ. 26, 272 (1991).
[52] S. Törnkvist, K. A. Pettersson, and G. Transrömer, Confusion by representation: On student's comprehension of the electric field concept, Am. J. Phys. 61, 335 (1993).

[53] E. Cavicchi, Experimenting with magnetism: Ways of learning of Joann and Faraday, Am. J. Phys. 65, 867 (1997).

[54] J. W. Creswell, Qualitative inquiry and research design: Choosing among five approaches (SAGE Publications, Thousand Oaks, CA, 2013).

[55] L. Lising and A. Elby, The impact of epistemology on learning: A case study from introductory physics, Am. J. Phys. 73, 372 (2005).

[56] K. Berthold, T. H. S. Eysink, and A. Renkl, Assisting selfexplanation prompts are more effective than open prompts when learning with multiple representations, Instr. Sci. 37, 345 (2009).

[57] E. M. Crowder, Gestures at work in sense-making science talk, J. Learn. Sci. 5, 173 (1996).

[58] F. Jeppsson, J. Haglund, T. G. Amin, and H. Strömdahl, Exploring the use of conceptual metaphors in solving problems on entropy, J. Learn. Sci. 22, 70 (2013).

[59] O. Parnafes, Developing explanations and developing understanding: Students explain the phases of the moon using visual representations, Cognit. Instr. 30, 359 (2012).

[60] NGSS Lead States, Next Generation Science Standards: For States, By States (2013).

[61] C. Turpen and N.D. Finkelstein, The construction of different classroom norms during Peer Instruction: Students perceive differences, Phys. Rev. ST Phys. Educ. Res. 6, 020123 (2010).

[62] B. Warren, C. Ballenger, M. Ogonowski, A. S. Rosebery, and J. Hudicourt-Barnes, Rethinking diversity in learning science: The logic of everyday sense-making, J. Res. Sci. Teach. 38, 529 (2001).

[63] H. T. Zimmerman, S. Reeve, and P. Bell, Family sensemaking practices in science center conversations, Sci. Educ. 94, 478 (2010). 